\title{
Oral disease in adults treated with hemodialysis: prevalence, predictors, and association with mortality and adverse cardiovascular events: the rationale and design of the ORAL Diseases in hemodialysis (ORAL-D) study, a prospective, multinational, longitudinal, observational, cohort study
}

Giovanni FM Strippoli ${ }^{1,2,3,4^{*}}$, Suetonia C Palmer ${ }^{5}$, Marinella Ruospo ${ }^{2}$, Patrizia Natale², Valeria Saglimbene ${ }^{1}$, Jonathan C Craig ${ }^{3}$, Fabio Pellegrini ${ }^{6}$, Massimo Petruzzi ${ }^{7}$, Michele De Benedittis ${ }^{7}$, Pauline Ford ${ }^{8}$, David W Johnson ${ }^{9}$, Eduardo Celia ${ }^{13}$, Ruben Gelfman ${ }^{13}$, Miguel R Leal ${ }^{12}$, Marietta Torok ${ }^{11}$, Paul Stroumza ${ }^{10}$, Anna Bednarek-Skublewska ${ }^{14}$, Jan Dulawa ${ }^{15}$, Luc Frantzen ${ }^{10}$, Juan Nin Ferrari ${ }^{16}$, Domingo del Castillo ${ }^{17}$, Jorgen Hegbrant ${ }^{2}$, Charlotta Wollheim², Letitzia Gargano ${ }^{2}$ and on behalf of the ORAL-D Investigators

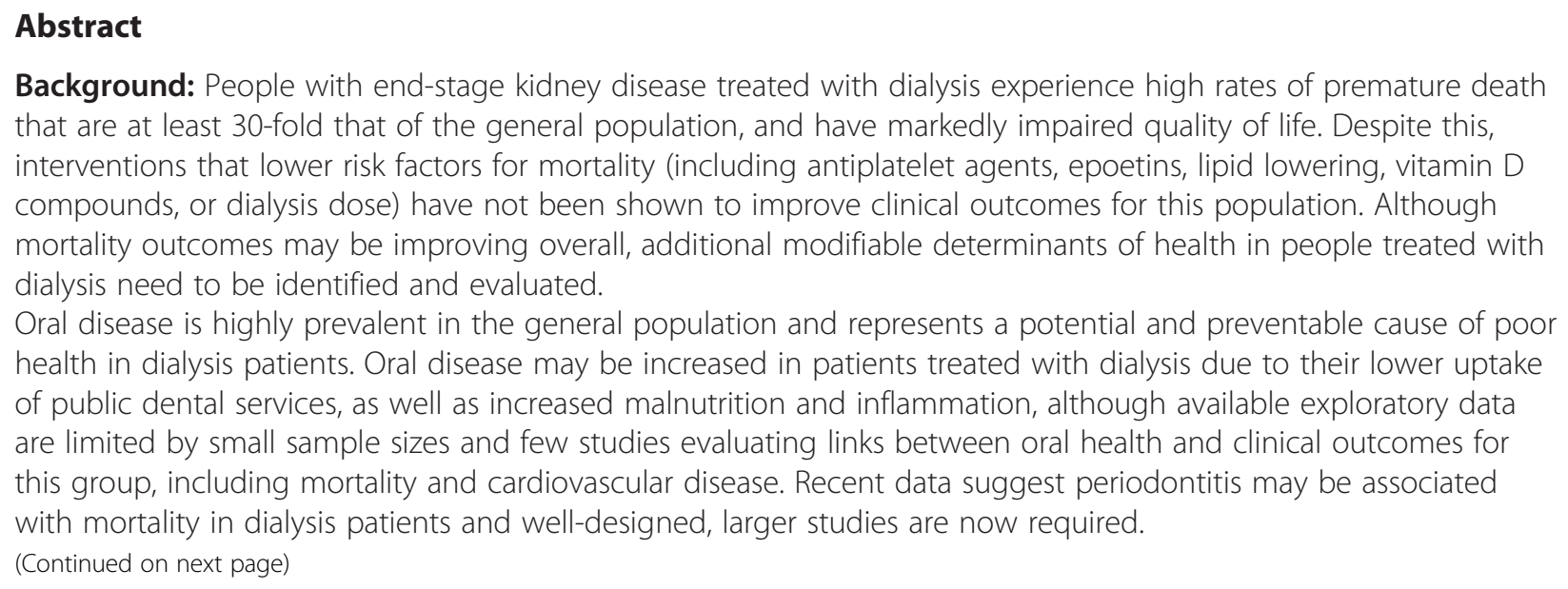
that are at least 30-fold that of the general population, and have markedly impaired quality of life. Despite this, interventions that lower risk factors for mortality (including antiplatelet agents, epoetins, lipid lowering, vitamin D compounds, or dialysis dose) have not been shown to improve clinical outcomes for this population. Although mortality outcomes may be improving overall, additional modifiable determinants of health in people treated with dialysis need to be identified and evaluated.

Oral disease is highly prevalent in the general population and represents a potential and preventable cause of poor health in dialysis patients. Oral disease may be increased in patients treated with dialysis due to their lower uptake of public dental services, as well as increased malnutrition and inflammation, although available exploratory data are limited by small sample sizes and few studies evaluating links between oral health and clinical outcomes for this group, including mortality and cardiovascular disease. Recent data suggest periodontitis may be associated with mortality in dialysis patients and well-designed, larger studies are now required.

* Correspondence: strippoli@negrisud.it

'Department of Clinical Pharmacology and Epidemiology, Consorzio Mario Negri Sud, Italy

${ }^{2}$ Diaverum Scientific Office, Lund, Sweden

Full list of author information is available at the end of the article 


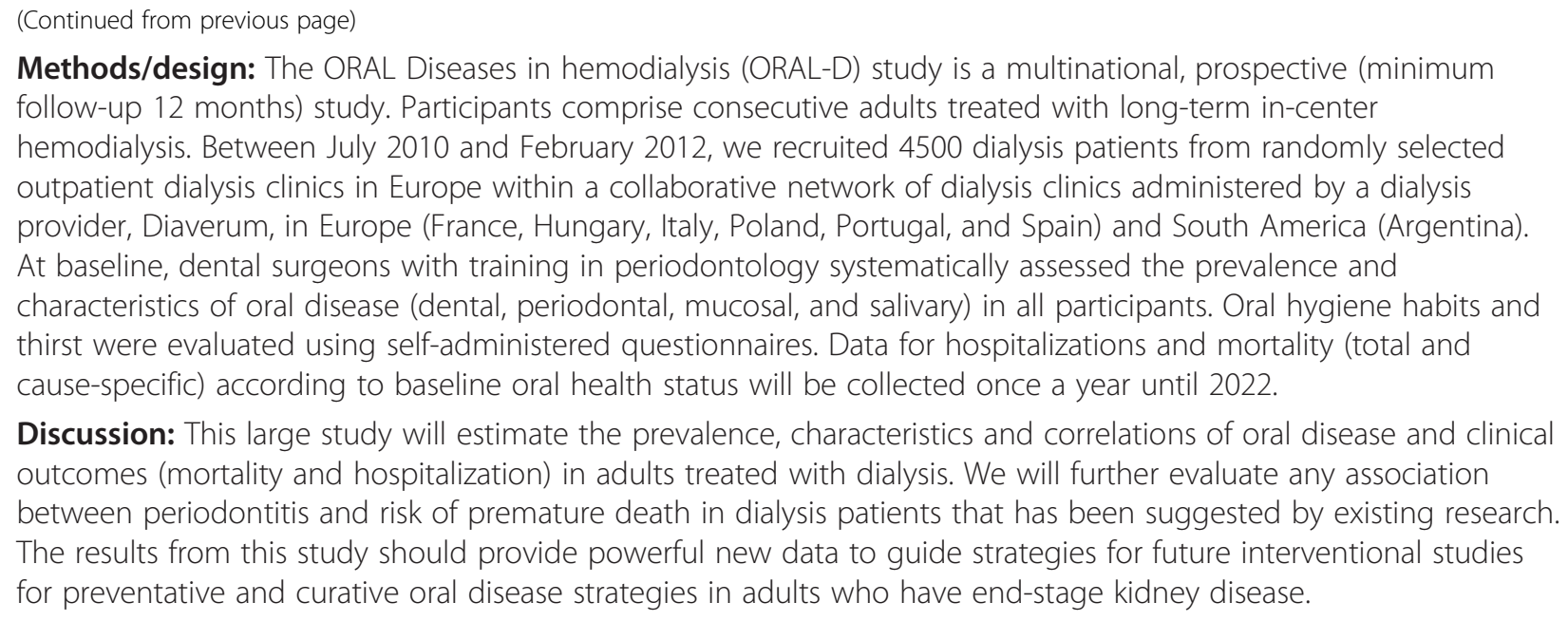

Discussion: This large study will estimate the prevalence, characteristics and correlations of oral disease and clinical outcomes (mortality and hospitalization) in adults treated with dialysis. We will further evaluate any association between periodontitis and risk of premature death in dialysis patients that has been suggested by existing research. The results from this study should provide powerful new data to guide strategies for future interventional studies for preventative and curative oral disease strategies in adults who have end-stage kidney disease.

Keywords: Chronic kidney disease, Oral disease, Periodontitis, Mortality, Prevalence

\section{Background}

The prevalence of chronic kidney disease (clinically-relevant structural kidney changes or urinary abnormalities, with or without reduced estimated glomerular filtration rate [below $60 \mathrm{ml} / \mathrm{min}$ per $1.73 \mathrm{~m}^{2}$ ]) [1] is increasing globally, due in part to international epidemics of obesity and diabetes mellitus. Approximately $10 \%$ to $15 \%$ of the global adult population is affected by chronic kidney disease [2-4]. In addition to an increasing prevalence, chronic kidney disease is associated with markedly impaired quality of life, sexual dysfunction, unemployment, depression, and premature mortality $[5,6]$. Moderate kidney disease (estimated glomerular filtration rate below $44 \mathrm{ml} / \mathrm{min}$ per $1.73 \mathrm{~m}^{2}$ and/or heavy proteinuria) is associated with a 2- to 3- fold increase in all-cause mortality compared with the general population and for dialysis patients the risk is much higher $[7,8]$. Despite poorer clinical outcomes, pharmacologic and dialysisrelated interventions (including anti-platelet agents, [9] dialysis dose, [10] early dialysis initiation, [11] vitamin D compounds, [12] erythropoietins [13], phosphodiesterase-5 inhibitors, [14] or antidepressant medication [15-20]) generally do not improve clinical outcomes or quality of life, particularly for those with end-stage kidney disease treated with dialysis. Exploration of additional and modifiable determinants of health in populations with chronic kidney disease would help prioritize the evaluation of novel intervention strategies to improve clinical outcomes.

Oral disease represents a potential and preventable cause of impaired health in people with chronic kidney disease. Oral disease, including dental decay and periodontitis, affects nearly all adults in the global population [21] and is amongst one of the most costly diseases to treat for many health systems $[21,22]$. Chronic disease is particularly linked to poorer oral health and greater unmet dental need, including untreated dental disease, self-reported poor oral health, and tooth loss [23]. In addition, individuals who have chronic kidney disease (estimated glomerular filtration rate below $60 \mathrm{ml} / \mathrm{min}$ per $1.73 \mathrm{~m}^{2}$ ) are much less likely than the general population to attend publicly available dental care, even when controlling for age, gender, race or ethnicity, language barriers, medical insurance and income [24]. Periodontal disease is associated with cardiovascular disease in the general population [25] and emerging data suggest a link between periodontitis and mortality in people with chronic kidney disease treated with dialysis [26,27]. Oral disease is associated with inflammation [28] and malnutrition (including the protein-energy wasting syndrome) $[29,30]$, which affect people who have chronic kidney disease disproportionately, and are considered linked risk factors for accelerated cardiovascular disease in this clinical setting (known as malnutrition, inflammation, and atherosclerosis [MIA] syndrome) [31]. The relative contributions of socioeconomic disadvantage, malnutrition and inflammation to the prevalence and outcomes of oral disease in people who have kidney disease require analysis in a large longitudinal study, ahead of potential interventional trials.

Existing data for the prevalence and severity of oral disease in chronic kidney disease patients are confined to a few studies that have small sample sizes and marked differences in the estimates of oral disease between studies that are not readily explained by study-level clinical or demographic characteristics [32]. The ORAL Diseases in hemodialysis (ORAL-D) study has been designed to survey the prevalence, severity, correlates, and outcomes of oral disease in a large consecutive population of 
adults with end-stage kidney disease treated with hemodialysis to assist the prioritization of future interventional research for oral disease in this population. Robust data linking oral health to relevant clinical outcomes may additionally identify the need for specific interventional trials in dialysis patients.

The ORAL-D study was specifically designed to explore the following questions:

1. Is the prevalence of oral disease higher in adults treated with hemodialysis and does the pattern of oral disease indicate/correlate with lower use of preventative dental services?

2. What are the important correlates of oral disease in hemodialysis patients including sociodemographic and clinical factors?

3. What is the prevalence of thirst and dysgeusia symptoms in adults treated with hemodialysis?

4. What are the characteristics and correlates of preventative oral habits including teeth brushing, attendance at dental care, flossing, and use of mouth wash?

5. Is there a relationship between biochemical and clinical performance measures used to evaluate quality of dialysis care and the prevalence and severity of oral disease?

6. What is the association between oral disease (dental, periodontal, salivary, or mucosal) and hospitalization or premature mortality in hemodialysis patients?

\section{Hypothesis}

In the largest cohort study of oral disease in dialysis patients to date (the ORAL Diseases in Hemodialysis [ORAL-D] study), we will test the hypothesis that oral disease is frequently experienced by patients with endstage kidney disease treated with hemodialysis and increases risk of total and cause-specific hospitalization and mortality when controlling for potentially confounding factors. We have evaluated oral hygiene habits and thirst in this population and whether biochemical and clinical performance measures of dialysis care are associated with increased risks of all forms of oral disease.

\section{Methods/design}

We received ethics approval for the ORAL Diseases in Hemodialysis (ORAL-D) study from the following responsible local Human Research Ethics Committees: Comitè de Protection des Personnes Sud-Medierranèe II (France), Komisja Bioetyczna, Slaskiego Uniwersytetu Medycznego W Katowicach (Poland), CE da Diaverum Portugal (Portugal), Comite Etico de Investigacion Clinica (CEIC) de la Fundaction Puygvert and Agencia Valenciana de Salud, Departament de Salut Valencia (Spain), and Szegedi Tudomanyegyetem, Szent-Gyorgyi albert klinikai kozpont, and Regionalis human orvosbiologiai kutatasetikai bizottsaga (Hungary). Ethics approval was not required for this type of study in Italy or Argentina. All participants provided written and informed consent prior to study initiation and patient enrolment. The study is being performed in accordance with the 2000 Edinburgh, Scotland Revision of the Declaration of Helsinki, applicable ICH guidelines and Guidelines on Research Practice.

\section{Study design}

This is a multinational, prospective (minimum 12 months' follow-up) study, in which approximately 4500 patients with end-stage kidney disease treated with outpatient in-center hemodialysis within a collaborative network of dialysis clinics administered by a dialysis provider (Diaverum) were enrolled between July 2010 and February 2012. The clinics included in this study were from dialysis communities with heterogeneity in social and economic circumstances and for which local investigators had committed to providing good-quality data during study follow-up.

\section{Patient population}

The study is multinational and open to all outpatient Diaverum haemodialysis treatment centers in selected countries in Europe (France, Hungary, Italy, Poland, Portugal, and Spain) and South America (Argentina).

Eligible patients have met the following inclusion criteria:

1. End-stage kidney disease

2. Currently on long-term hemodialysis for any duration

3. Aged 18 years or over

4. Treating team agreeable to patient's involvement in the study

5. Able to provide written and informed consent

\section{Study procedures}

Patients had met the inclusion criteria and all provided informed consent. Processes to identify and screen all potential recruits were established within each center in consultation with the ORAL-D study Steering Committee. Patient consent forms were approved by the Human Research Ethics Committee before the beginning the study. A sample consent form and patient information sheet was provided to participating sites. Participating sites filed a copy of the approved consent form and information sheet for their center with the coordinating study office. The patient had an initial consultation with study personnel to discuss study participation, which included a preliminary eligibility check. The patient was also given an information sheet for the study. If consent was provided by the patient, a copy of the signed 
consent form and information sheet was given to the participant. The participant gave written and informed consent before enrollment or completion of any study-specific procedures. The ORAL-D study Steering Committee monitored the medical literature and any other relevant information that might have impacted on the ongoing conduct of the study.

The study commenced on the day of enrollment. At enrollment, all participants underwent: 1) collection of demographic and clinical data including dialysis-related care; 2) completion of self-administered questionnaires on oral hygiene and thirst; and 3) comprehensive and systematic oral examination, including assessment of dental, periodontal, mucosal, and salivary characteristics (including $\mathrm{pH}$ and flow).

\section{Demographic and clinical data}

The collection of demographic, clinical/laboratory and dialysis-related data were performed by the local treating physician on standardized case report forms within one month of enrollment. Relevant data were obtained from clinical databases linked to the patient via a standardized identification code. Standardized data variables included age, gender, race, country of residence, educational, marital and occupational status, alcohol intake, smoking history, physical activity, housing, distance from dialysis unit, menopausal status, body mass index, protein catabolic rate, family income, financial stress, food intake, cause of kidney disease, diabetic status and other comorbid conditions, medication prescription, and serum parameters including hemoglobin, phosphorus, parathyroid hormone, calcium, ferritin, albumin, cholesterol, and dialysis parameters. We included specific collection of data for medications to treat depression and anxiety that may have dry mouth as a side-effect as well as oral anticoagulants to evaluate their association with oral bleeding.

\section{Self-administered questionnaires}

At baseline, all participants completed self-administered questionnaires to evaluate oral hygiene habits, [33] and thirst [34]. Oral hygiene habit data included questions about visits for dental care, brushing, mouth wash use, and dental floss practices, and duration of oral hygiene each day (Figure 1). The dialysis thirst inventory was used to ask patients about thirst as a clinical symptom

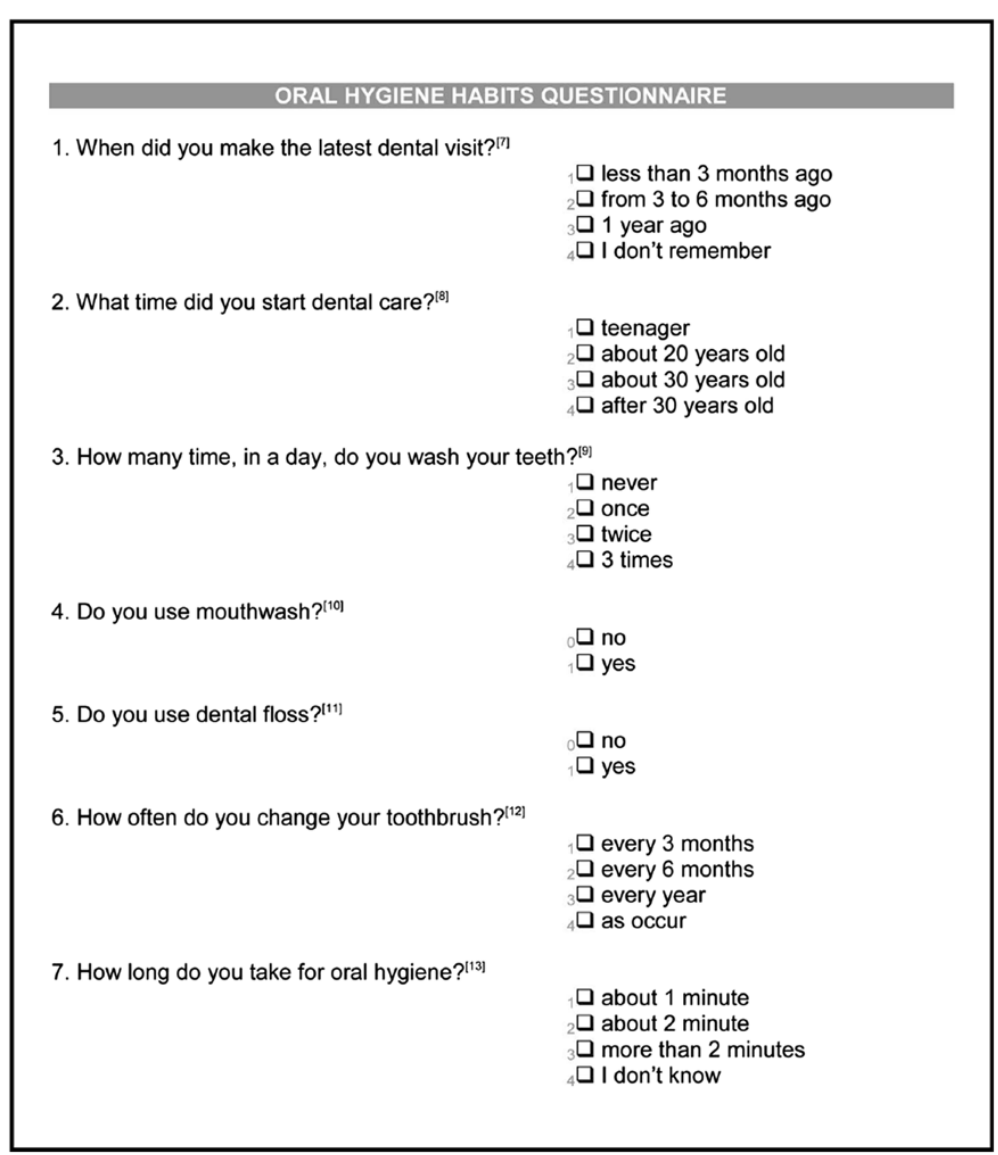

Figure 1 Self-administered questionnaire on oral habits. 
including at night, the effect of social life on thirst, and thirst in relation to dialysis (Figure 2).

\section{Oral examination}

All patients were examined at baseline by a qualified dental surgeon with training in periodontology in each country who had been centrally trained on the protocol and methods used for the study. The standardized oral examination included analysis of dental, periodontal, mucosal and salivary health. The oral examination occurred in the dialysis unit on the day of dialysis. We performed the dental and periodontal examination before dialysis treatment started (to minimize excessive bleeding due to heparin administration). We collected saliva before and after dialysis therapy and participants completed all questionnaires during dialysis. We performed oral visits in a specifically set up room at the dialysis clinical with an appropriate chair and mobile light source, or in the dialysis room using a light-emitting diode (LED) headlamp, based on patient preference. We used a standard sterile oral examination kit containing a dental examination mirror, ball-tip periodontal probe (calibrated in millimeters), tweezers, masks, bib, tissue wipes, cotton rolls and a biodegradable tray.

1. Dental examination

The DMFT index quantifies dental caries, fillings, and tooth loss. In this study, the DMFT index was calculated centrally for 32 teeth in the adult dentition including the four wisdom teeth or third molars. The dentist also recorded the total number of teeth (maximum 32) and the presence or absence of enamel hypoplasia and dental attrition or erosion. If dental attrition or erosion was present, the dentist indicated the likely cause. The dentist also recorded the presence of any denture (partial or total).

2. Periodontal examination The standardized periodontal examination included the Periodontal Probing Depth (PPD), the Clinical Attachment Loss (CAL) score and the Bleeding on Probing (BOP) indices (Figure 3).

The Periodontal Probing Depth (PPD) was the distance between the free gingival margin and the apical extent of the periodontal pocket. The tip of

\section{DIALYSIS THIRST INVENTORY}

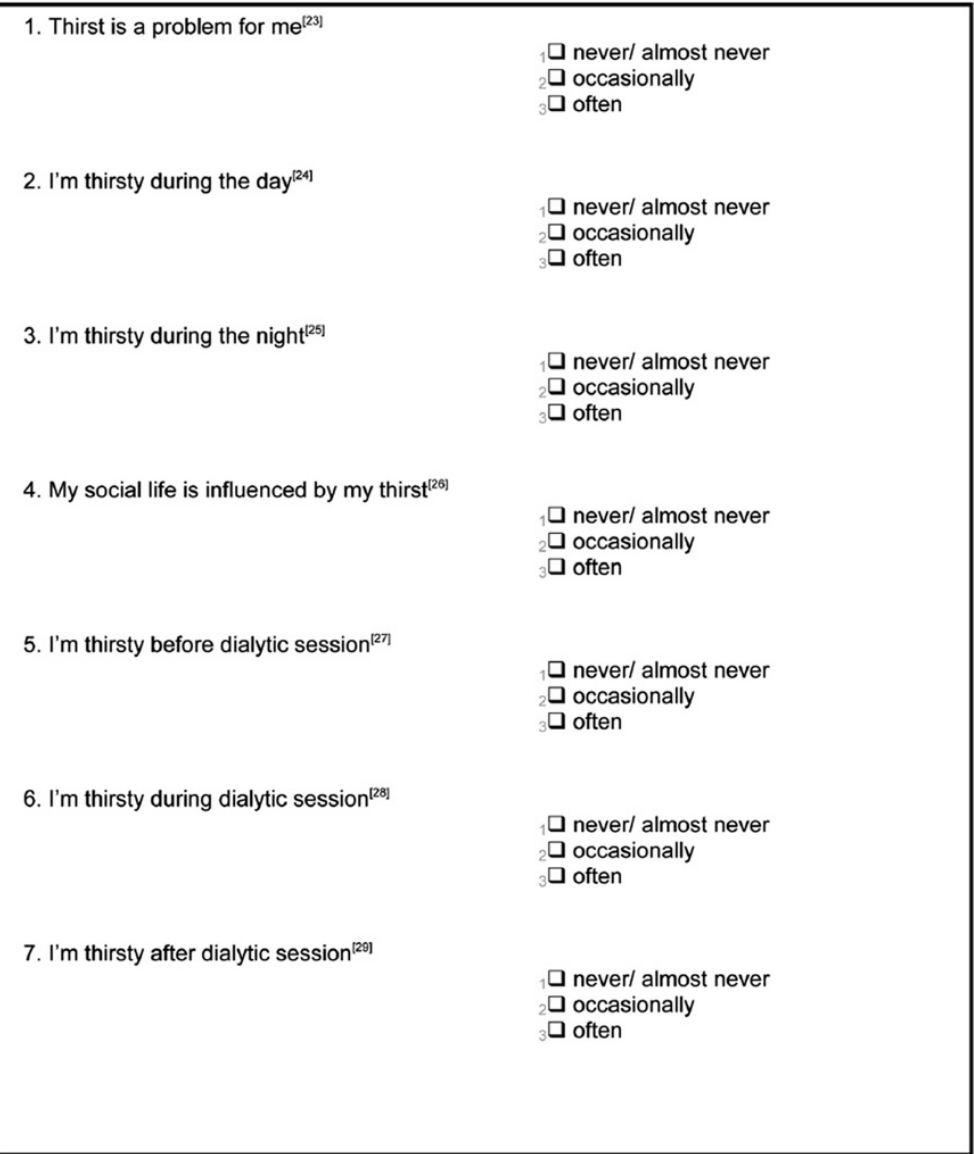

Figure 2 Self-administered dialysis thirst inventory questionnaire. 


\section{ORAL HEALTH IN HEMODIALYSIS \\ SECTION FOR THE DENTAL SURGEON}

\section{PERIODONTAL EVALUATION}

SCORING

PPD \& CAL - Periodontal Probing Depth and Clinical Attachment Loss

T Indicate 3 PPD measurements for each tooth surface (vestibular, lingual), and GM-CEJ distance (mm), using the periodontal probe. ${ }^{[37-164]}$

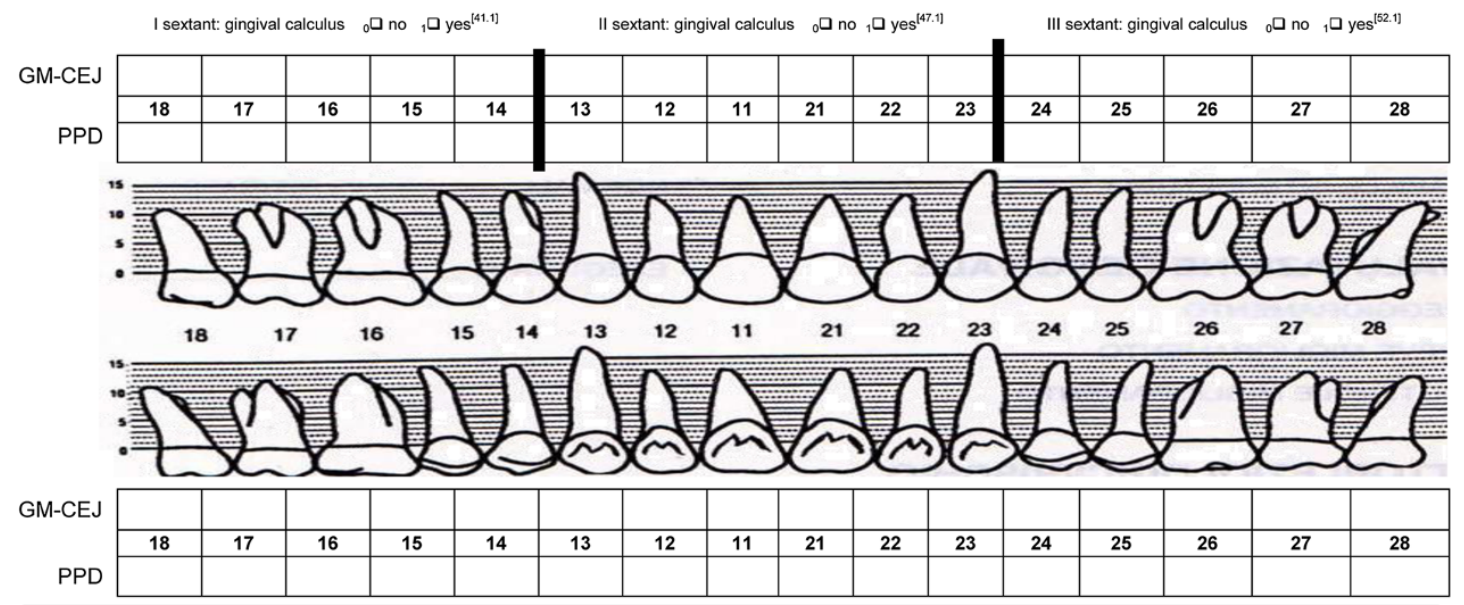

\begin{tabular}{|c|c|c|c|c|c|c|c|c|c|c|c|c|c|c|c|c|}
\hline \multicolumn{17}{|l|}{ GM-CEJ } \\
\hline & 48 & 47 & 46 & 45 & 44 & 43 & 42 & 41 & 31 & 32 & 33 & 34 & 35 & 36 & 37 & 38 \\
\hline PPD & & & & & & & & & & & & & & & & \\
\hline
\end{tabular}
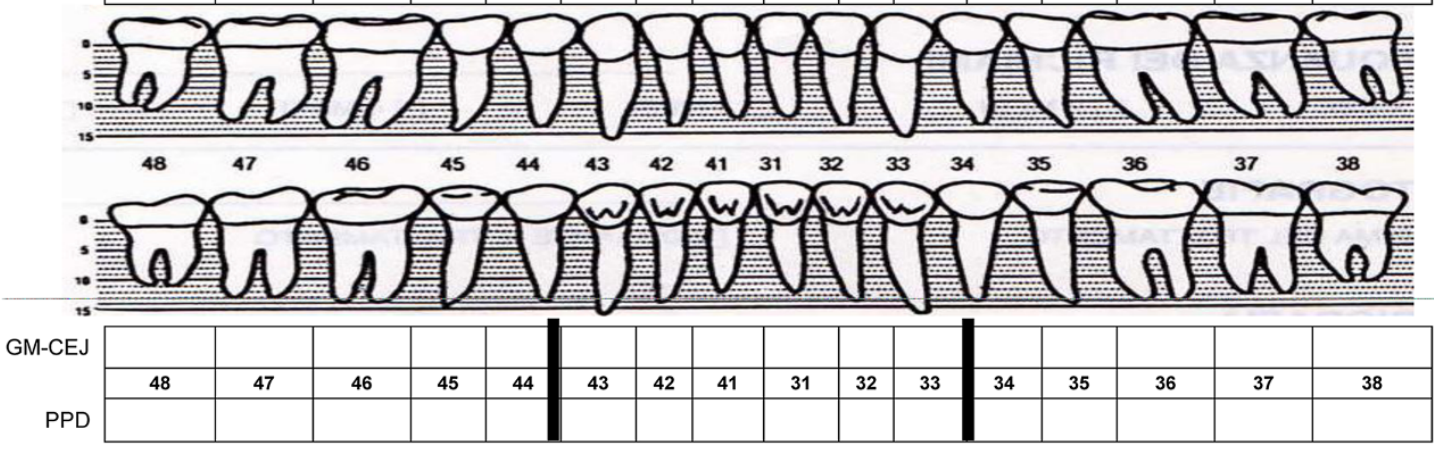

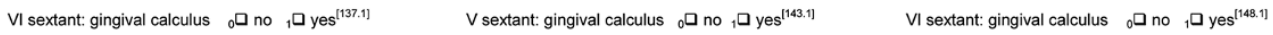

BOP- Bleeding On Probing

Each of the four surfaces (buccal, lingual, mesial and distal) is given a score from 0-1. ${ }^{\text {[165-292] }}$

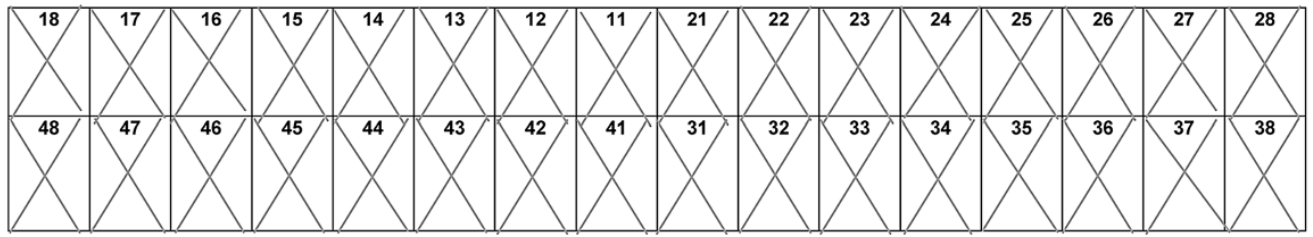

Figure 3 Standardized periodontal evaluation at baseline. 
the periodontal probe was placed with light pressure (10 to 20 grams) into the gingival sulcus, which is an area of potential space between a tooth and the surrounding tissue. The first marking visible above the pocket indicated the measurement of the pocket depth. Three PPD measurements for each of the vestibular and lingual aspects of the tooth were recorded. A healthy pocket depth is approximately 3 $\mathrm{mm}$ without bleeding on probing. Depths greater than $3 \mathrm{~mm}$ are associated with "attachment loss" of the tooth to the surrounding alveolar bone, characteristic of periodontitis. The PPD score was calculated as a mean value expressed in millimeters and determined as the total PPD divided by the number of sites examined.

The same periodontal probe was used to measure the distance between the cementum-enamel junction (CEJ) and the free gingival margin (GM). Clinical Attachment Loss (CAL) was calculated as the sum of these distances, according to the standard formula CAL $=$ PPD + (GM - CEJ $)$. The CAL score for each patient was calculated as the sum of the mean PPD (sum of all values divided by the number of sites examined (6 per tooth)) and the mean (GM-CEJ) (sum of all values divided by the number of sites examined (2 per tooth)).

The Bleeding On Probing (BOP) index evaluated the buccal, lingual, mesial and distal sulci of all teeth recommended by the World Health Organization based on the tendency to bleed after a standard stimulus and indicating periodontal inflammation. The four surfaces of each tooth were tested to provide a maximum total of 128 sites. A final index was obtained centrally and expressed as a percentage of sites positive for bleeding on probing. The BOP index was performed before the patient had received heparin administration for dialysis treatment.

3. Mucosal examination

The dental surgeon asked the participant about symptoms of oral pain, burning and dysgeusia (altered sense of taste). For pain and burning symptoms the patient indicated the severity of symptoms on a Visual Analog Scale reporting a value from 1 to 10 . The dental surgeon also evaluated the presence of ulceration, white or red mucosal lesions, neoformation, petechial-ecchymosis, thrush, herpes, geographical tongue, scrotal tongue, uremic breath, previous surgery, and other lesions, indicating the oral location, when present. Drugrelated gingival overgrowth (hypertrophy) was assessed as present or absent.

4. Salivary indices

The participant was then asked not to eat, drink, or smoke for an hour before the salivary analyses were performed. To estimate the salivary flow rate, the patient chewed on a standard weight (1 gram) of paraffin wax for 60 seconds and swallow the formed saliva. Then, while chewing the paraffin intensively, the saliva was spat into plastic sterile calibrated containers ( 5 centimeters in diameter and provided with a plastic cap) during the following 5 minutes. The stimulated salivary flow rate was expressed in milliliters per minute and measured before (predialysis) and after dialysis (post-dialysis). The saliva was then used to measure the salivary buffering capacity using the CRT buffer system and salivary $\mathrm{pH}$ was determined using the Merck Universal indicator system (Merck, Darmstadt, Germany).

\section{Clinical follow-up and data collection}

During follow-up, patients continued to receive usual standardized care according to dialysis center protocols at the entire discretion of the treating clinical team.

Data for total and cause-specific hospitalization and mortality will be obtained through data linkages to a centralized database within the Diaverum network. In this database, every change in patient status in the clinics is updated by the managing clinician on a monthly basis, including change of survival status or from present in clinic or hospitalized, with causes for death and hospitalization and days of hospital stay.

A cardiovascular-related death or hospitalization includes death or hospitalization attributed to acute myocardial infarction, pericarditis, atherosclerotic heart disease, cardiomyopathy, cardiac arrhythmia cardiac arrest, valvular heart disease, pulmonary edema, congestive cardiac failure, cerebrovascular accident including intracranial hemorrhage, ischemic brain damage including anoxic encephalopathy, or mesenteric infarction or ischemia of bowel. An infection-related death includes septicemia due to internal vascular access, central nervous system infection (brain abscess, meningitis, encephalitis), septicemia due to peripheral vascular disease or gangrene, or other cause, cardiac infection (endocarditis), pulmonary infection (pneumonia or influenza), abdominal infection (peritonitis, perforated bowel, diverticular disease, gallbladder), or genito-urinary infection (urinary tract infection, pyelonephritis, renal abscess).

\section{Outcomes}

The primary outcome for the study is total (all-cause) mortality associated with different types of oral disease (such as edentulism, DMFT score, or periodontitis). Secondary outcomes include death attributable to cardiovascular causes and death due to infection. Additional secondary outcomes include total and causespecific hospitalization (cardiovascular or infection), and 
prevalence and characteristics of oral diseases (edentulism, DMFT score, periodontitis, oral pain, dysgeusia, precancerous and cancerous lesions, salivary flow rates and saliva buffering capacity). Prevalence of oral hygiene habits, thirst, and dysgeusia will also be included in secondary analyses.

\section{Rationale for the number of participants}

The sample size for this study is 4700 participants. Assuming that the prevalence of the exposure (i.e. periodontitis) is about $40 \%$ and that 1 -year mortality in the exposed group is $15 \%$, an overall sample of 4700 individuals (2820 with periodontitis and 1880 without) is sufficient to detect a relative reduction of at least $20 \%$ in 1year mortality (i.e. absolute risk difference of $3 \%$; odds ratio equal to 0.77 ) with a power of $80 \%$, where correlation between exposure and other adjustment covariates $=0.10$ and type I error $=0.05$.

The large number of participants have also been recruited so that relatively rare conditions such as precancerous lesions of the mouth/tongue (estimated likely prevalence $1 \%$ to $3 \%$ [21]) can be evaluated. Recruitment has been competitive within the dialysis network to ensure that at least 4700 valid analyses with complete datasets and visits are available.

\section{Statistical analysis}

Analysis will conform to a predefined statistical analysis plan agreed between the steering committee and study statisticians before analysis is commenced. Baseline sociodemographic and clinical characteristics will be calculated and expressed as mean (standard deviation) or median $\left(25^{\text {th }}\right.$ to $75^{\text {th }}$ percentile) for continuous variables and number (proportion) for categorical variables. Prevalence and characteristics of oral disease (dental, periodontal, mucosal, and salivary) will be calculated as number (proportion) affected for categorical variables and mean (standard deviation) or median $\left(25^{\text {th }}\right.$ to $75^{\text {th }}$ percentile) for continuous variables. Multivariable logistic regression models will be built to investigate the influence of patient demographic and clinical characteristics on risks of oral disease. We will include as potential variables in analysis: age, sex, ethnicity, country or residence, educational status, living situation, occupation status, smoking, BMI, self-reported appetite, income, financial strain, comorbidity score, diabetes, existing cardiovascular disease, depression score, blood pressure, protein catabolic rate, hemoglobin, albumin, phosphorus, cholesterol, ferritin, parathyroid hormone, and duration on dialysis.

We will use Cox proportional hazard models for analysis of mortality and hospitalization outcomes. We will check for confounders, interactions and multicollinearity among independent variables. The final models will be adjusted for all confounders and baseline covariables judged to have clinical importance. The significance level will be set at 0.05 . All analyses will be performed using macro routines written in SAS Language (Release 9.1, SAS Institute Inc., Cary, NC; 2002-2003; http://www. sas.com/).

\section{Discussion}

Chronic kidney disease is an important and increasing global public health problem that is associated with marked loss of quality of life and increased premature cardiovascular disease and mortality. End-stage kidney disease, the most severe form of kidney disease, is associated with profoundly reduced survival and a heavy symptom burden, although existing interventions to improve clinical outcomes in this population are generally lacking. Oral disease may represent an important cause of impaired quality of life and worse clinical outcomes in dialysis patients. However, on the basis of current evidence, data for the characteristics of oral health and preventative oral hygiene habits in dialysis population are sparse. Additional large-scale studies of oral health in this population would assist the prioritization of future research including appropriate interventional trials. The ORAL-D study is the first large and comprehensive survey of oral disease in adults treated with long-term hemodialysis. We will evaluate the prevalence, severity and correlates of oral disease and evaluate the relationship between oral disease and clinical outcomes (hospitalization and mortality) in this population.

\section{Abbreviations}

BOP: Bleeding on Probing; CAL: Clinical Attachment Loss; CRT: Caries Risk Test; CEJ: Cementum-Enamel Junction; DMFT index: Decayed, Missing, Filled Teeth index; ICH guidelines: International Conference of Harmonisation guidelines; GM: Gingival Margin; ORAL-D study: The ORAL Diseases in hemodialysis study; PPD: Periodontal Probing Depth.

\section{Competing interests}

The authors declare that they have no competing interests. SP receives an unrestricted fellowship from the Consorzio Mario Negri Sud from Amgen Dompé and is a L'Oreal For Women in Science Australia and New Zealand 2012 Fellow.

\section{Authors' contributions}

GFMS; Principal Investigator; the conception, design of the study, oversight of study conduct; SP; participated in design of the study, drafting of statistical analysis plan and initial drafting of manuscript; MR; participation in design of the study, oversight and conduct of all practical aspects of the study, critical review of the manuscript; PN; data collection and entry, critical review of the manuscript; VS, statistical analysis; JC, participation in design of the study, critical review of the manuscript; FP; statistical expertise; MP, MDB; participation in design of the study, oversight and conduct of all practical aspects of the study, critical review of the manuscript; PF, DJ; participation in design of the study, critical review of the manuscript; PS, LF, MT, MRL, EC, RG, $A B-S, J D, J N F, D D C, J H, C W$; participation in design of the study, oversight and conduct of practical aspects of the study, critical review of the manuscript. All authors have given final approval of the version to be published.

\section{Authors' information}

Giovanni F.M. Strippoli, MD, MPH, MM, PhD, Department of Clinical Pharmacology and Epidemiology, Consorzio Mario Negri Sud, Italy; Diaverum Scientific Office, Lund, Sweden; School of Public Health, University of Sydney, 
Australia, Department of Emergency and Organ Transplantation, University of Bari, Italy;

Suetonia C. Palmer, MBChB, PhD; University of Otago Christchurch, New Zealand

Marinella Ruospo, MSc; Diaverum Scientific Office, Lund, Sweden Patrizia Natale, MSc; Diaverum Scientific Office, Lund, Sweden Valeria Saglimbene, MSc; Department of Clinical Pharmacology and Epidemiology, Consorzio Mario Negri Sud, Italy

Jonathan C. Craig, MBChB, PhD; School of Public Health, University of Sydney, Australia

Fabio Pellegrini, MSc; Consorzio Mario Negri Sud; "Casa Sollievo della Sofferenza" Hospital, IRCCS, San Giovanni Rotondo (FG), Italy

Massimo Petruzzi, Dental clinic, University of Bari, Italy

Michele De Benedittis, Dental clinic, University of Bari, Italy

Pauline J. Ford, BDSC (Hons), BDentSt, PhD, GCHEd, The University of

Queensland, School of Dentistry, Brisbane, Australia

David W. Johnson, MBBS (Hons), PhD, Centre for Kidney Disease Research, University of Queensland at Princess Alexandra Hospital, Brisbane, Australia Paul Stroumza, MD, Diaverum Medical Office, France

Luc Frantzen, MD, Diaverum Medical Office, France

Marietta Törok, MD, Diaverum Medical Office, Hungary

Miguel R Leal, MD, Diaverum Medical Office, Portugal

Eduardo Celia, MD, Diaverum Medical Office, Argentina

Ruben Gelfman, MD, Diaverum Medical Office, Argentina

Anna Bednarek-Skublewska, MD, Diaverum Medical Office, Poland; and Department of Nephrology, Medical University School of Lublin, Poland Jan Dulawa, MD, Diaverum Medical Office, Poland and Department of Internal Medicine, Metabolic Diseases, Medical University of Silesia, Poland Juan Nin Ferrari, MD, Diaverum Medical Office, Uruguay Domingo Del Castillo, MD, Diaverum Medical Office, Spain Jörgen Hegbrant, MD, PhD, Diaverum Medical Office, Sweden Charlotta Wollheim, MSc, Diaverum Medical Office, Sweden Participating centers, facilitators, steering and organizing committee members

Italy: N Dambrosio, G Paparella, M Sambati, C Donatelli, F Pedone, VA Cagnazzo, R Antinoro, F Torsello, C Saturno, G Giannoccaro, S Maldera, E Boccia, M Mantuano, R Di Toro Mammarella, M Meconizzi, PF Steri, C Riccardi, A Flammini, L Moscardelli, M Murgo, N San Filippo, S Pagano, G Marino, G Montalto, S Cantarella, B Salamone, G Randazzo, D Rallo, A Maniscalco, M Fici, A Lupo, P Pellegrino, R Fichera, A D'Angelo, N Falsitta, L Gargano, P Natale

Poland: E. Bocheńska-Nowacka, A. Jaroszyński, J. Drabik, M. Birecka, D. Daniewska, M. Drobisz, K. Doskocz, G. Wyrwicz

Portugal: L Inchaustegui, C Outerelo, D Sousa Mendes, A Mendes, J Lopes, J Barbas, C Madeira, A Fortes, R Vizinho, A Cortesão, E Almeida, M Santos France: C Boriceanu, S Frantzen-Trendel

Hungary: K Albert, I Csaszar, E Kiss, D Kosa, A Orosz, J Redl, L Kovacs, E Varga, M Szabo, K Magyar, G Kriza, E Zajko, A Bereczki, J Csikos, A Kuti, A Mike, K

Steiner, E Nemeth, K Tolnai, A Toth, J Vinczene, Sz Szummer, E Tanyi, R Toth, M Szilvia, K Nagy, Ö Bajusz, I Pinke, G Decsi, L Gyergyoi, Zs Jobba, Zs Zalai, Á Zsedenyi, G Kiss, M Pinter, M Kereszturi

Spain: A. Bernat, B. De la Torre, A. Lopez, J. Martín , G. Cuesta, R.M. Rodriguez, F. Ros, M. Garcia, E. Orero, E. Ros.

Argentina: S Raña, M Serrano, S Claros, M Arias, L Petracci, M Arana, P De Rosa, A Gutierrez, M Simon, V Vergara, M Tosi, M Cernadas, I Vilamajó, D Gravac, M Paulón, L Penayo, G Carrizo, M Ghiani, G Perez, O Da Cruz, D Galarce, M Gravielle, E Vescovo, R Paparone, C Mato Mira, E Mojico, O Hermida, D Florio, M Yucoswky, W Labonia, D Rubio, G Di Napoli, A Fernandez, H Altman, J Rodriguez, S Serrano, G Valle, M Lobos, V Acosta, G Corpacci, M Jofre, L Gianoni, G Chiesura, M Capdevila, J Montenegro, J Bequi, J Dayer, A Gómez, C Calderón, E Abrego, C Cechín, J García, J Corral, M Natiello, A Coronel, M Muñiz, V Muñiz, A Bonelli, F Sanchez, S Maestre, S Olivera, M Camargo, V Avalos, E Geandet, M Canteli, A Escobar, E Sena, S Tirado, A Peñalba, G Neme, M Cisneros, R Oliszewski, V Nascar, M Daud, S Mansilla, A Paredes Álvarez, L Gamín, M Arijón, M Coombes, M Zapata Doctors of Dental Surgery.

M Petruzzi (Dental clinic, University of Bari, Italy), M De Benedittis (Dental clinic, University of Bari) J Szkutnik (Department of Functional Masticatory Disorders Medical University of Lublin); J Sieczkarek (Chair and Department of Periodontology Medical University of Lublin); M Garcia Gallart (independent dentist), C Mendieta (Periodontology Professor, University of Barcelona); A Capelo (Department of Estomatology, Centro Hospitalar Lisboa Norte, Lisboa); A Caetano, K MacGregor, S Silva Pinheiro, L Martins, D Leitão, C Izidoro (independent dentists); G Bava (Buenos Aires); A Bora (Caleta Olivia); H Gorena (Córdoba); T Calderón (Mendoza); R Dupuy, N Alonso (Tucumán); V Siciliano (Comodoro Rivadavia).

\section{Acknowledgements}

Funding was received from Diaverum AB for the conduct of this study. Part funding was received from LCO, Le Cliniche Odontoiatriche. The funding body had no role in the design, collection, analysis or interpretation of data: in writing of the manuscript; or in the decision to submit the manuscript for publication. GS, MR, PN, PS, LF, MT, ML, EC, RG, AB, JD, J N-F, DC, JH, CW and LG are employees of Diaverum AB.

\section{Author details}

'Department of Clinical Pharmacology and Epidemiology, Consorzio Mario Negri Sud, Italy. ${ }^{2}$ Diaverum Scientific Office, Lund, Sweden. ${ }^{3}$ School of Public Health, University of Sydney, Sydney, Australia. ${ }^{4}$ Department of Emergency and Organ Transplantation, University of Bari, Bari, Italy. ${ }^{5}$ University of Otago Christchurch, Addington, New Zealand. ${ }^{6}$ Consorzio Mario Negri Sud; "Casa Sollievo della Sofferenza" Hospital, IRCCS, San Giovanni Rotondo (FG), Italy. ${ }^{7}$ Dental clinic, University of Bari, Bari, Italy. ${ }^{8}$ The University of Queensland, School of Dentistry, Brisbane, Australia. ${ }^{9}$ Centre for Kidney Disease Research, University of Queensland at Princess Alexandra Hospital, Brisbane, Australia. ${ }^{10}$ Diaverum Medical Office, Lyon, France. ${ }^{11}$ Diaverum Medical Office, Budapest, Hungary. ${ }^{12}$ Diaverum Medical Office, Sintra, Portugal. ${ }^{13}$ Diaverum Medical Office, Capital Federal, Argentina. ${ }^{14}$ Diaverum Medical Office, Poland; and Department of Nephrology, Medical University School of Lublin, Lublin, Poland. ${ }^{15}$ Diaverum Medical Office, Poland and Department of Internal Medicine, Metabolic Diseases, Medical University of Silesia, Silesia, Poland. ${ }^{16}$ Diaverum Medical Office, Montevideo, Uruguay. ${ }^{17}$ Diaverum Medical Office, Madrid, Spain.

Received: 17 November 2012 Accepted: 16 April 2013

Published: 19 April 2013

\section{References}

1. National Kidney Foundation: K/DOQI clinical practice guidelines for chronic kidney disease: evaluation, classification, and stratification. Am J Kidney Dis 2002, 39(2 Suppl 1):S1-266.

2. Chen J, Wildman RP, Gu D, Kusek JW, Spruill M, Reynolds K, Liu D, Hamm $L L$, Whelton PK, He J: Prevalence of decreased kidney function in Chinese adults aged 35 to 74 years. Kidney Int 2005, 68(6):2837-2845.

3. Coresh J, Byrd-Holt D, Astor BC, Briggs JP, Eggers PW, Lacher DA, Hostetter $\mathrm{TH}$ : Chronic kidney disease awareness, prevalence, and trends among U. S. adults, 1999 to 2000. J Am Soc Nephrol 2005, 16(1):180-188.

4. Singh NP, Ingle GK, Saini VK, Jami A, Beniwal P, Lal M, Meena GS: Prevalence of low glomerular filtration rate, proteinuria and associated risk factors in North India using Cockcroft-Gault and Modification of Diet in Renal Disease equation: an observational, cross-sectional study. BMC Nephrol 2009, 17(10):4.

5. Evans RW, Manninen DL, Garrison LP Jr, Hart LG, Blagg CR, Gutman RA, Hull $A R$, Lowrie EG: The quality of life of patients with end-stage renal disease. New Engl J Med 1985, 312(9):553-559.

6. Murtagh FE, ddington-Hall J, Higginson IJ: The prevalence of symptoms in end-stage renal disease: a systematic review. Adv Chronic Kidney Dis 2007, 14(1):82-99.

7. Go AS, Chertow GM, Fan D, McCulloch CE, Hsu CY: Chronic kidney disease and the risks of death, cardiovascular events, and hospitalization. $N$ Engl J Med 2004, 351(13):1296-1305.

8. Hemmelgarn BR, Manns BJ, Lloyd A, James MT, Klarenbach S, Quinn RR, Wiebe N, Tonelli M: Relation between kidney function, proteinuria, and adverse outcomes. JAMA 2010, 303(5):423-429.

9. Palmer SC, Di Micco L, Razavian M, Craig JC, Perkovic V, Pellegrini F, Copetti M, Graziano G, Tognoni G, Jardine M, et al: Effects of antiplatelet therapy on mortality and cardiovascular and bleeding outcomes in persons with chronic kidney disease: a systematic review and meta-analysis. Ann Intern Med 2012, 156(6):445-459. 
10. Eknoyan G, Beck GJ, Cheung AK, Daugirdas JT, Greene T, Kusek JW, Allon M, Bailey J, Delmez JA, Depner TA, et al: Effect of dialysis dose and membrane flux in maintenance hemodialysis. N Engl J Med 2002, 347(25):2010-2019.

11. Cooper BA, Branley P, Bulfone L, Collins JF, Craig JC, Fraenkel MB, Harris A, Johnson DW, Kesselhut J, Li J, et al: A randomized, controlled trial of early versus late initiation of dialysis. N Engl J Med 2010, 363(7):609-619.

12. Palmer SC, McGregor DO, Macaskill P, Craig JC, Elder GJ, Strippoli GF: Meta-analysis: vitamin D compounds in chronic kidney disease. Ann Intern Med 2007, 147(12):840-853.

13. Palmer SC, Navaneethan SD, Craig JC, Johnson DW, Tonelli M, Garg AX, Pellegrini F, Ravani P, Jardine M, Perkovic V, et al: Meta-analysis: Erythropoiesis-stimulating agents in patients with chronic kidney disease. Ann Intern Med 2010, 153(1):23-33.

14. Vecchio M, Navaneethan SD, Johnson DW, Lucisano G, Graziano G, Querques M, Saglimbene V, Ruospo M, Bonifati C, Jannini EA, et al: Treatment options for sexual dysfunction in patients with chronic kidney disease: a systematic review of randomized controlled trials. Clin J Am Soc Nephrol 2010, 5(6):985-995.

15. Ancarani E, Biondi B, Bolletta A, Cestra D, De BE, Nirchi MA, Nucera G, Orlandi N, Persichetti S, Scaccia F, et al: Major depression complicating hemodialysis in patients with chronic renal failure: A multicenter, double-blind, controlled clinical trial of S- adenosyl-L-methionine versus placebo. Curr Ther Res Clin Exp 1993, 54(6):680-686.

16. Baines LS, Joseph JT, Jindal RM: Prospective randomized study of individual and group psychotherapy versus controls in recipients of renal transplants. Kidney Int 2004, 65:1937-1942.

17. Blumenfield M, Levy NB, Spinowitz B, Charytan C, Beasley CM Jr, Dubey AK Solomon RJ, Todd R, Goodman A, Bergstrom RF: Fluoxetine in depressed patients on dialysis. Int J Psychiatry Med 1997, 27(1):71-80.

18. Duarte PS, Miyazaki MC, Blay SL, Sesso R: Cognitive-behavioral group therapy is an effective treatment for major depression in hemodialysis patients. Kidney Int 2009, 76:414-421.

19. Koo JR, Yoon JY, Joo MH, Lee HS, Oh JE, Kim SG, Seo JW, Lee YK, Kim HJ Noh JW, et al: Treatment of depression and effect of antidepression treatment on nutritional status in chronic hemodialysis patients. Am J Med Sci 2005, 329(1):1-5

20. Lii YC, Tsay SL, Wang TJ: Group intervention to improve quality of life in haemodialysis patients. J Clin Nurs 2007, 16(11c):268-275.

21. Petersen PE, Bourgeois D, Ogawa H, Estupinan-Day S, Ndiaye C: The global burden of oral diseases and risks to oral health. Bull World Health Organ 2005, 83:661-669.

22. Dye BA, Tan S, Smith V, Lewis BG, Barker LK, Tohornton-Evans G, et al: Trends in oral health status: United States, 1988-1994 and 1999-2004. National Center for Health Statistics. Vital Health Stat 2007, 11(248):1-92.

23. Griffin SO, Barker LK, Griffin PM, Cleveland JL, Kohn W: Oral health needs among adults in the United States with chronic diseases. J Am Dent Assoc 2009, 140(10):1266-1274

24. Grubbs V, Plantinga LC, Tuot DS, Powe NR: Chronic kidney disease and use of dental services in a United States public healthcare system: a retrospective cohort study. BMC Nephrol 2012, 13(1):16.

25. Lockhart PB, Bolger AF, Papapanou PN, Osinbowale O, Trevisan M, Levison ME, Taubert KA, Newburger JW, Gornik HL, Gewitz MH, et al: Periodontal disease and atherosclerotic vascular disease: Does the evidence support an independent association? Circulation 2012, 125(20):2520-2544.

26. Chen LP, Chiang CK, Peng YS, Hsu SP, Lin CY, Lai CF, Hung KY: Relationship between periodontal disease and mortality in patients treated with maintenance hemodialysis. Am J Kidney Dis 2011, 57(2):276-282.

27. Kshirsagar AV, Craig RG, Moss KL, Beck JD, Offenbacher S, Kotanko P, Klemmer PJ, Yoshino M, Levin NW, Yip JK, et al: Periodontal disease adversely affects the survival of patients with end-stage renal disease. Kidney Int 2009, 75(7):746-751.

28. Beck JD, Slade G, Offenbacher S: Oral disease, cardiovascular disease and systemic inflammation. Periodontol 2000, 23(1):110-120.

29. Fouque D, Kalantar-Zadeh K, Kopple J, Cano N, Chauveau P, Cuppari L, Franch $\mathrm{H}$, Guarnieri $\mathrm{G}$, Ikizler TA, Kaysen $\mathrm{G}$, et al: A proposed nomenclature and diagnostic criteria for protein-energy wasting in acute and chronic kidney disease. Kidney Int 2007, 73(4):391-398.

30. Moynihan P, Petersen PE: Diet, nutrition and the prevention of dental diseases. Public Health Nutr 2004, 7(1A):201-226.
31. Pecoits-Filho $R$, Lindholm B, Stenvinkel $P$ : The malnutrition, inflammation, and atherosclerosis (MIA) syndrome - the heart of the matter. Nephrol Dial Transplant 2002, 17(Suppl 11):28-31.

32. Ruospo M, Palmer SC, Vecchio M, Gargano L, Petruzzi M, De Benedictis M, Strippoli G: Oral disease in people with chronic kidney disease: Meta-analysis of prevalence and association with clinical outcomes. Nephrol Dial Transplant 2012, 27(Suppl 2):ii1-ii549.

33. Al-Shammari KF, Al-Ansari JM, Al-Khabbaz AK, Dashti A, Honkala EJ: Self-reported oral hygiene habits and oral health problems of Kuwaiti adults. Med Princ Pract 2007, 16(1):15-21.

34. Bots $C P$, Brand HS, Veerman EC, Valentijn-Benz M, Van Amerongen BM, Valentijn RM, Vos PF, Bijlsma JA, Bezemer PD, Ter Wee PM, et al: Interdialytic weight gain in patients on hemodialysis is associated with dry mouth and thirst. Kidney Int 2004, 66(4):1662-1668.

\section{doi:10.1186/1471-2369-14-90}

Cite this article as: Strippoli et al: Oral disease in adults treated with hemodialysis: prevalence, predictors, and association with mortality and adverse cardiovascular events:

the rationale and design of the ORAL Diseases in hemodialysis (ORALD) study, a prospective, multinational, longitudinal, observational, cohort study. BMC Nephrology 2013 14:90

\section{Submit your next manuscript to BioMed Central and take full advantage of:}

- Convenient online submission

- Thorough peer review

- No space constraints or color figure charges

- Immediate publication on acceptance

- Inclusion in PubMed, CAS, Scopus and Google Scholar

- Research which is freely available for redistribution 